\title{
Competitor density and food concentration: an empirical approach to elucidate the mechanism of seasonal succession of two coexisting Bosmina
}

\author{
Hiroyuki Mano ${ }^{1, *}$, Masaki Sakamoto ${ }^{2}$ \\ ${ }^{1}$ Research Center for Environmental Risk, National Institute for Environmental Studies, 16-2 Onogawa, Tsukuba City, Ibaraki \\ 305-8506, Japan \\ ${ }^{2}$ Department of Environmental Engineering, Toyama Prefectural University, 5180 Kurokawa, Imizu City, Toyama 939-0398, Japan
}

\begin{abstract}
To examine the density effect and food concentration in the competitive output of two Bosmina species, the population growths of Bosmina fatalis were investigated by manipulating the density of $B$. longirostris and the concentration of algae. The $B$. fatalis density did not increase in conditions with abundant $B$. longirostris regardless of the food concentrations. The $B$. fatalis increased only at low densities of $B$. longirostris with high food concentrations. Based on the current results, a possible mechanism underlying the seasonal shift from B. longirostris to B. fatalis in Japanese eutrophic lakes will be explored below.
\end{abstract}

Key words: Bosmina, Cladocera, competition, priority effect, seasonal succession

\section{INTRODUCTION}

Natural communities in freshwater ecosystems show seasonal successions, which are caused by changes in environmental conditions and biological interactions (Connell and Slatyer 1977, Drake 1991, Murdock et al. 2010). Seasonal succession of two small coexisting bosminid cladocerans is commonly observed in Japanese eutrophic lakes, where Bosmina longirostris dominate the zooplankton community in spring and B. fatalis dominate in summer (Fig. 1).

There are two possible mechanisms explaining this succession pattern. The first is selective predation by Leptodora kindtii, which occurs in early summer (Chang and Hanazato 2003). The direct effect of temperature could not explain the seasonal succession of two Bosmina species (Hanazato and Yasuno 1985a), and thus Chang and Hanazato (2003) concluded that selective predation by $L$. kindtii on $B$. longirostris influenced the competition between two populations of Bosmina. The second is food density (Hanazato and Yasuno 1987). When the two species were reared together with the same initial numbers of individuals with a large food supply, B. fatalis overcame $B$. longirostris. The opposite occurred with a small food supply. These results indicate that the threshold food concentration (TFC), the ambient concentration of food that allows population losses to be compensated for by the production of offspring (Lampert 1977, Kreutzer and Lampert 1999), for B. longirostris is lower than that for $B$. fatalis. Moreover, a high population density of $B$. longirostris inhibits the subsequent increase of $B$. fatalis, indicating a density effect of $B$. longirostris on the population growth of $B$. fatalis. However, the importance of density effects in the seasonal succession of cladocerans has not http://dx.doi.org/10.5141/ecoenv.2013.267

(c) $\$$ This is an Open Access article distributed under the terms of
the Creative Commons Attribution Non-Commercial Licens
(http://creativecommons.org/licenses/by-nc/3.0/) which
permits unrestricted non-commercial use, distribution, and reproduction in any
medium, provided the original work is properly cited.
Received 01 April 2013, Accepted 07 November 2013

*Corresponding Author

E-mail: h-mano@pwri.go.jp

Tel: +81-29-879-6777 


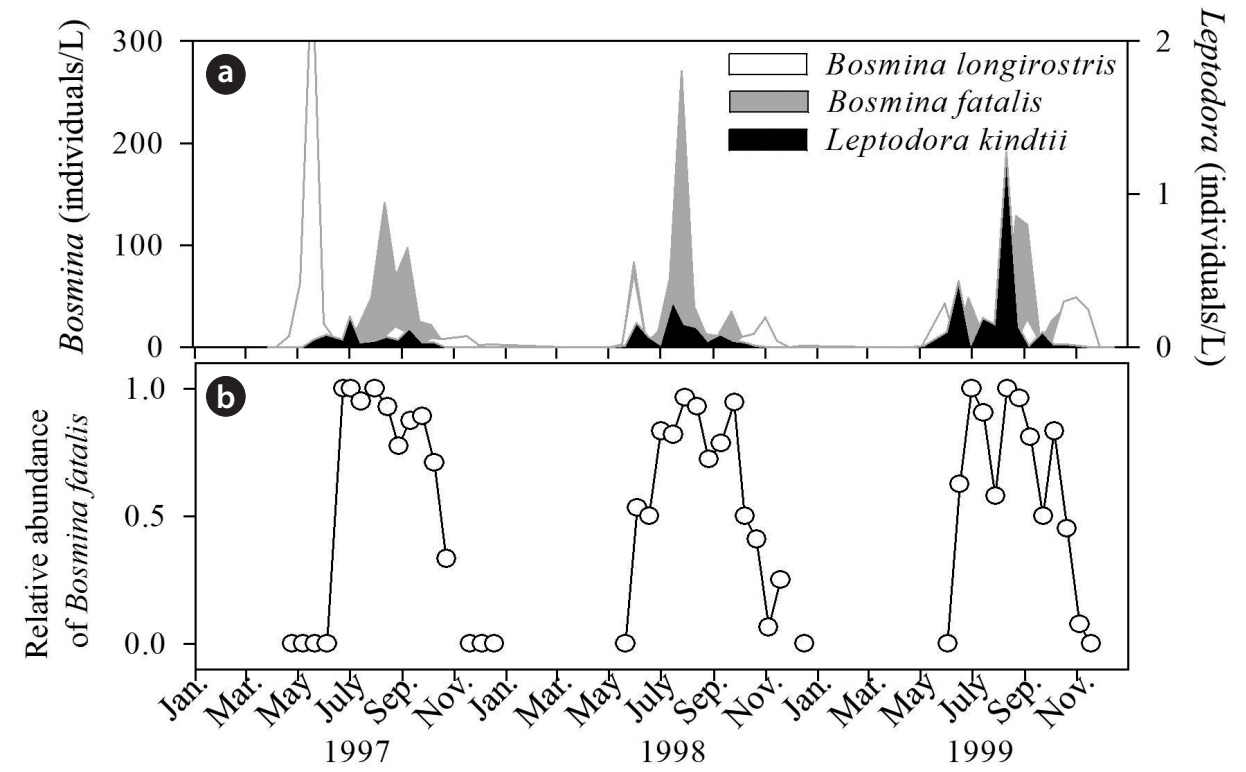

Fig. 1. Seasonal and reciprocal succession of two Bosmina species in Lake Suwa from 1997 to 1999 (redrawn from Chang and Hanazato 2003). (a) Seasonal changes in densities of B. longirostris, B. fatalis, and L. kindtii, and (b) relative abundance of B. fatalis (density of B. fatalis divided by total Bosmina density).

been experimentally examined.

Here, the question of whether a high population density of $B$. longirostris inhibits the growth of a B. fatalis population will be addressed. In the experiment, the summer decline of B. longirostris was simulated by preparing high and low density groups representing their seasonal populations. Food resources were also manipulated to examine whether the effect of $B$. longirostris on the population growth of $B$. fatalis is affected by food concentrations.

\section{MATERIALS AND METHODS}

The stock culture of each species (single clone) was established from an individual collected in Lake Suwa $\left(36^{\circ} 2^{\prime}\right.$ $\left.\mathrm{N}, 138^{\circ} 5^{\prime} \mathrm{E}\right)$ a year before the experiment. The animals were maintained in a 20-L cylindrical polyethylene tank ( $30 \mathrm{~cm}$ diameter, $31 \mathrm{~cm}$ height) with $20 \mathrm{~L}$ of dechlorinated tap water for two weeks before the experiment. The tanks (one tank for each Bosmina species) were kept at a constant temperature of $22 \pm 1{ }^{\circ} \mathrm{C}$ and a regime of $16 \mathrm{~h}$ light and $8 \mathrm{~h}$ darkness. The green alga, Chlorella vulgaris (Chlorella Industry Co. Ltd., Fukuoka, Japan; $2 \times 10^{9}$ cells), was introduced into tanks as food for Bosmina every second day. The culture medium in each tank was exchanged 24 $\mathrm{h}$ before the experiment, in which aggregated individuals near the light source (Bosmina shows positive phototaxis) were transferred to a new tank by pipetting. After the ex- change of medium, no food was added into the tank until the start of the experiment.

The experiments were carried out in sixteen 2-L polymethylpentene beakers (Sanplatec Co. Ltd., Osaka, Japan) as experimental aquariums. To create conditions of high and low B. longirostris densities, $40 \mathrm{ml}$ of the B. longirostris stock culture was added to 8 experimental beakers and $200 \mathrm{~mL}$ to the other beakers before the inoculation of $B$. fatalis, respectively. The numbers of individuals in three samples of the $40-\mathrm{mL}$ and $200-\mathrm{mL}$ stock culture media were counted, and the initial densities (mean \pm SE) of B. longirostris $\left(\mathrm{N}_{\mathrm{Bl}-0}\right)$ were $22.0 \pm 1.0$ individuals/ $\mathrm{L}$ and $126.0 \pm 8.4$ individuals/L in low- and high-density conditions, respectively. The balance of each beaker was filled with dechlorinated tap water so that each contained $2 \mathrm{~L}$. Experimental aquariums were assigned to low and high food concentrations of $0.5 \times 10^{5}$ and $5 \times 10^{5}$ cells $/ \mathrm{mL}$, respectively, every second day. All combinations of $B$. longirostris initial density and food concentration were run in four replicates. Experimental aquariums were maintained for eight days to increase populations of $B$. longirostris.

Eight days after the start of the experiments, the contents of the beakers were gently mixed, and $500 \mathrm{~mL}$ of water from each was sampled to estimate the density of $B$. longirostris $\left(\mathrm{N}_{\mathrm{BL}-8}\right)$. Each of the collected media was filtered through a $40 \mu \mathrm{m}$ mesh net and preserved in a $4 \%$ sugarformalin solution. After the sampling, B. fatalis was introduced into each beaker by adding $40 \mathrm{~mL}$ of gently mixed 


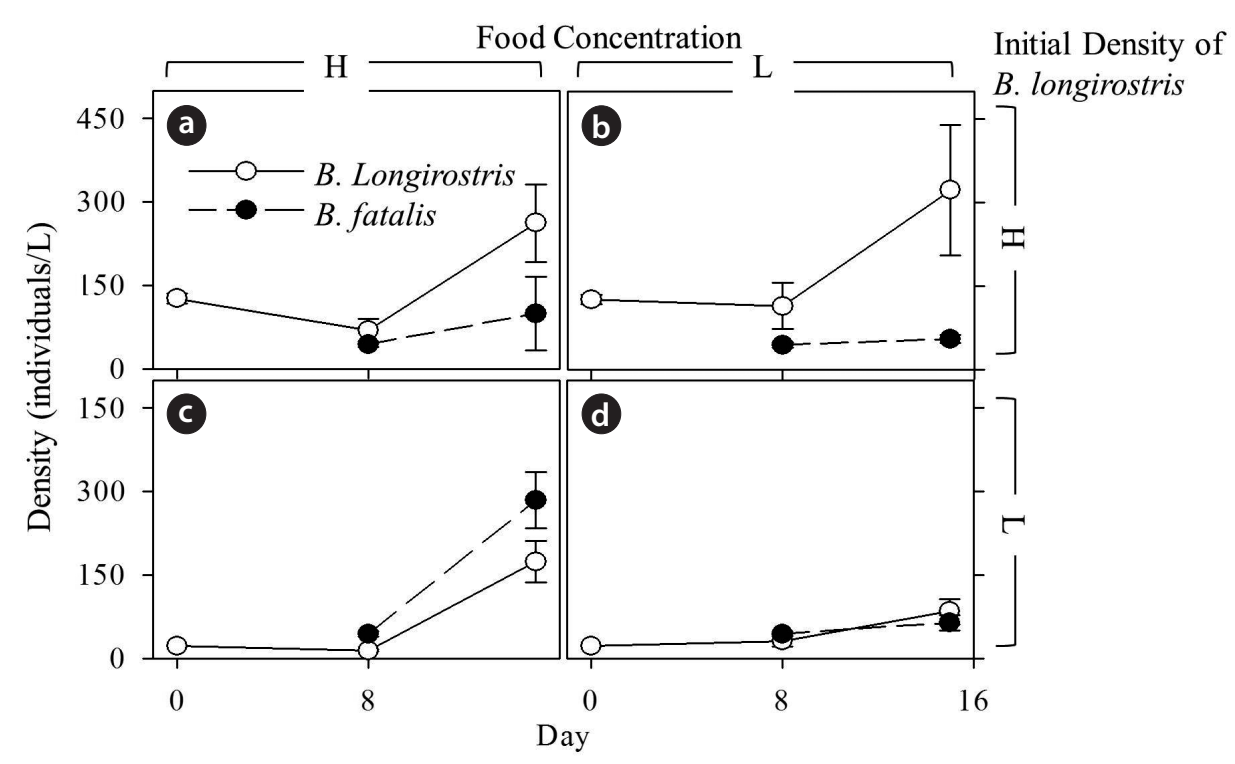

Fig. 2. Changes in density (mean $\pm \mathrm{SE}$ ) of Bosmina longirostris and B. fatalis cultured with high (a, c) or low (b, d) food concentrations, which is $5 \times 10^{5}$ or 0.5 $\times 10^{5}$ cells/mL, respectively. Upper $(a, b)$ and lower $(c, d)$ figures show results of high and low B. longirostris initial density treatments, respectively. High- and low initial density of $B$. longirostris, are $22.0 \pm 1.0$ individuals/L and $126.0 \pm 8.4$ individuals/L, respectively. Open and filled circles indicate $B$. longirostris and $B$. fatalis, respectively.

stock culture medium. The density of $B$. fatalis $\left(\mathrm{N}_{\mathrm{BE}-8}\right)$ was estimated by counting the individual numbers in $40 \mathrm{~mL}$ of medium obtained from the other three samplings. Fifteen days after the start of experiments, the water remaining in each beaker $(1.54 \mathrm{~L})$ was filtered, and the samples were preserved in a $4 \%$ sugar-formalin solution. To estimate the densities of B. fatalis and B. longirostris at 15 days $\left(\mathrm{N}_{\mathrm{Bf}-}\right.$ ${ }_{15}$ and $\mathrm{N}_{\mathrm{Bl}-15}$ ), the number of each species in each sample was counted under a dissecting microscope and the total was recalculated into number per liter. The experiment was conducted under the same laboratory conditions as used for the stock cultures.

Population densities of B. longirostris and B. fatalis were analyzed to test the hypothesis. To confirm the $B$. longirostris density treatment and to examine the temporal change in its density for each condition, the population densities of $B$. longirostris at 8 and 15 days $\left(\mathrm{N}_{\mathrm{Bl}-8}\right.$ and $\mathrm{N}_{\mathrm{Bl}-15}$ ) were analyzed with three-way repeated-measures ANOVA with time, initial density, and food concentration. The effects of $B$. longirostris population density and food concentration on the population density of B. fatalis $\left(\mathrm{N}_{\mathrm{Bf}-}\right.$ ${ }_{15}$ ) were tested with two-way ANOVA. To test increases in the population density of $B$. fatalis for each condition, a multiple comparison between the density of $B$. fatalis $\left(\mathrm{N}_{\mathrm{Bf}-8}\right)$ and the B. fatalis density of each condition at 15 days $\left(\mathrm{N}_{\mathrm{Bf}-15}\right)$ was performed using Dunnett's test. Before statistical analyses, the densities of $B$. longirostris and $B$. fatalis were log-transformed to achieve variance homo- geneity. Statistical analyses were conducted with $\mathrm{R}$ ver. 2.11.1 (R Development Core Team 2010).

\section{RESULTS AND DISCUSSION}

Temporal changes in densities of $B$. longirostris and $B$. fatalis cultured with high and low food concentrations were shown in Fig. 2. Although density treatment and time significantly affected the density of $B$. longirostris, there were no effects of food concentration or interaction terms (Table 1). These results confirmed that the density of $B$. longirostris increased with time irrespective of food concentrations.

The $\mathrm{N}_{\mathrm{Bf}-8}$ value was $43.3 \pm 4.6$ individuals/L (Fig. 2). The values of $\mathrm{N}_{\mathrm{Bf}-15}$ were influenced by B. longirostris density, food concentration, and the interaction term between them (Table 2). Only the $\mathrm{N}_{\mathrm{Bf}-15}$ in the condition with low initial density of $B$. longirostris and high food concentration was significantly higher than all $\mathrm{N}_{\mathrm{Bf}-8}$ (Dunnett's test, $t=3.718, P=0.007$ ). These results support the prediction that the growth of $B$. fatalis population was inhibited by the abundant $B$. longirostris. That $B$. fatalis increased only with a low $B$. longirostris density at a high food concentration suggests the presence of a density-dependent effect.

Results suggest that food competition can be a possible mechanism underlying the observed density-dependent effect of B. longirostris. In previously conducted compe- 
Table 1. The result of three-way repeated-measures ANOVA with time, initial density, and food concentration for population densities of $B$. longirostris at 8 and 15 days

\begin{tabular}{|c|c|c|c|c|}
\hline Source of variation & $\mathrm{Df}^{*}$ & $\mathrm{MS}^{* *}$ & $F^{* * *}$ & $P^{* * * *}$ \\
\hline \multicolumn{5}{|l|}{ Between beakers } \\
\hline Initial density & 1 & 9.562 & 24.902 & $<0.001$ \\
\hline Food concentration & 1 & 0.058 & 0.152 & 0.703 \\
\hline Initial density $\times$ food concentration & 1 & 0.257 & 0.669 & 0.429 \\
\hline Error $^{* * * * * *}$ & 12 & 0.384 & & \\
\hline \multicolumn{5}{|l|}{ Within beakers } \\
\hline Time & 1 & 17.305 & 40.419 & $<0.001$ \\
\hline Time $\times$ initial density & 1 & 0.537 & 1.254 & 0.285 \\
\hline Time $\times$ food concentration & 1 & 1.482 & 3.461 & 0.087 \\
\hline Time $\times$ initial density $\times$ food concentration & 1 & 0.652 & 1.523 & 0.241 \\
\hline Error ${ }^{* * * * * *}$ & 12 & 0.428 & & \\
\hline
\end{tabular}

"Degrees of freedom, ${ }^{* *}$ Mean of squares, ${ }^{, * * *} \mathrm{~F}$ value, ${ }^{* * * * *}$ Probability, ${ }^{* * * * * *}$ Error term for between- beakers variables, ${ }^{* * * * * * *}$ Error term for within-beakers variable Time and interactions of the between-beakers variables and the within-beaker variable.

Table 2. The result of two-way ANOVA with initial density of B. longirostris, and food concentration for the density of $B$. fatalis at 15 days $\left(\mathrm{N}_{\mathrm{Bf}-15}\right)$

\begin{tabular}{lcccc}
\hline \multicolumn{1}{c}{ Source of variation } & $\mathbf{d f}^{*}$ & MS $^{* *}$ & $\boldsymbol{F}^{* * *}$ & $\boldsymbol{P}^{* * * *}$ \\
\hline Initial density of B. longirostris & 1 & 2.833 & 6.028 & 0.030 \\
Food concentration & 1 & 2.325 & 4.946 & 0.046 \\
Initial density $\times$ food concentration & 1 & 2.218 & 4.728 & 0.049 \\
Error & 12 & 0.467 & & \\
${ }^{*}$ Degrees of freedom, ${ }^{* *}$ Mean of squares, ${ }^{* * * *} \mathrm{~F}$ value, ${ }^{* * * * *}$ Probability.
\end{tabular}

tition experiments, B. fatalis was depressed by B. longirostris at low food concentrations (Hanazato and Yasuno 1987, Chang and Hanazato 2004). Therefore, B. fatalis may have a higher TFC than does $B$. longirostris. In the present experiment, the algal concentration in the lowfood conditions might be comparable with the TFC value for B. fatalis and higher than that for B. longirostris. In the condition with a high food concentration and a high density of $B$. longirostris, consumption by abundant $B$. longirostris individuals might decrease the algal concentration down to the TFC of $B$. fatalis. On the other hand, in the condition with a high food concentration and a low density of $B$. longirostris, $B$. fatalis was able to feed enough to reproduce. Previous studies showed that when they had the same initial density, the larger of two species was a better competitor than the smaller species under high food conditions because it could feed more (Romanovsky and Feniova 1985). As B. fatalis is larger than B. longirostris (Hanazato and Yasuno 1987), the feeding rate of $B$. $f a$ talis may be higher than that of $B$. longirostris and thus be dominant under conditions with a high food concentration and a low density of $B$. longirostris.

\section{CONCLUSION}

The population shift from $B$. longirostris to $B$. fatalis is commonly observed during the early summer season in Japanese eutrophic lakes, as shown in Fig. 1 (Hanazato and Yasuno 1985b, Chang and Hanazato 2003). The present results demonstrate that the seasonal succession unconditionally requires very low population densities of $B$. longirostris. L. kindtii is an effective predator, which can reverse the dominance relationship between the two species through selective predation of $B$. longirostris (Chang and Hanazato 2003, 2004). In this study, laboratory experiments were conducted by using $B$. longirostris and $B$. fatalis collected from one site, Lake Suwa. Because B. longirostris is a cosmopolitan species and B. fatalis inhabits in East and Southeast Asia, they can present intraspecific variations in traits related to food competition. To test the effect of the intraspecific variations on the density effect of B. longirostris on the population growth of B. fatalis, further experiments by using the two species from other lakes are required. Investigating the density effect of species that are already present in a community on other species that appear in the community at some later time may help us to explain seasonal successions in zooplankton communities in natural lakes and ponds.

\section{ACKNOWLEDGMENTS}

The authors deeply appreciate Yoshinari Tanaka and Kwang-Hyeon Chang for their valuable comments and suggestions on this work. This study was partly supported 
by Grants-in-Aid to Masaki Sakamoto (No. 23510031) and to Shosaku Kashiwada (No. 23310026) from Japan Society for the Promotion of Science.

\section{LITERATURE CITED}

Chang KH, Hanazato T. 2003. Seasonal and reciprocal succession and cyclomorphosis of two Bosmina species (Cladocera, Crustacea) co-existing in a lake: their relationship with invertebrate predators. J Plankton Res 25: 141-150.

Chang KH, Hanazato T. 2004. Predation impact of Leptodora kindtii on population dynamics and morphology of Bosmina fatalis and B. longirostris in mesocosms. Freshw Biol 49: 253-264.

Connell JH, Slatyer RO. 1977. Mechanisms of succession in natural communities and their role in community stability and organization. Am Nat 111: 1119-1144.

Drake JA. 1991. Community-assembly mechanics and the structure of an experimental species ensemble. Am Nat 137: 1-26.

Hanazato T, Yasuno M. 1985a. Effect of temperature in the laboratory studies on growth, egg development and first parturition of five species of Cladocera. Jpn J Limnol 46: 185-191.
Hanazato T, Yasuno M. 1985b. Population dynamics and production of cladoceran zooplankton in the highly eutrophic Lake Kasumigaura. Hydrobiologia 124: 13-22.

Hanazato T, Yasuno M. 1987. Experimental studies on competition between Bosmina longirostris and Bosmina fatalis. Hydrobiologia. 154: 189-199.

Kreutzer C, Lampert W. 1999. Exploitative competition in differently sized Daphnia species: a mechanistic explanation. Ecology 80: 2348-2357.

Lampert W. 1977. Studies on the carbon balance of Daphnia pulex DeGeer as related to environmental conditions. IV. Determination of the "threshold" concentration as a factor controlling the abundance of zooplankton species. Arch Hydrobiol Suppl 48: 361-368.

Murdock JN, Gido KB, Dodds WK, Bertrand KN, Whiles MR. 2010. Consumer return chronology alters recovery trajectory of stream ecosystem structure and function following drought. Ecology 91: 1048-1062.

Romanovsky YE, Feniova IY. 1985. Competition among Cladocera: effect of different levels of food supply. Oikos 44: 243-252.

R Development Core Team. 2010. R: A language and environment for statistical computing. R Foundation for Statistical Computing, R Foundation for Statistical Computing, Vienna, Austria. http://www.R-project.org. Accessed 2 July 2010. 